\title{
Improving the Management of Ecological Safety on the Basis of Studies of Atmospheric Deposition in the Effect Area of Aluminum Production
}

\author{
Natalya I. Ianchenko* and Anatoly N. Baranow \\ National Research Irkutsk State Technical University \\ 83 Lermontov Str., Irkutsk, 664074, Russia
}

Received 20.01.2015, received in revised form 27.02.2015, accepted 17.03.2015

Spend snegohimicheskaya shooting, made the collection of precipitation of rain and snow in the area of the city of Bratsk, studied the chemical composition, a map of the changes the acidity of the snow cover in the zone of influence of emissions of primary aluminum and pulp and paper mill. The basis used GIS technology must be reliable data system or other field observations of the changing parameters in the environment in correlation to the actual conditions of a given period (used raw, wind speed, rainfall, air temperature).

Keywords: fluorine, sulfur, sodium, emissions, snow cover, atmospheric deposition.

\section{Совершенствование управления}

экологической безопасностью

на основе исследования атмосферных выпадений

в районе влияния производства алюминия

Н.И. Янченко, А.Н. Баранов

Иркутский национальный

исследовательский технический университет Россия, 664074, Иркутск, Лермонтова, 83

Проведена снегохимическая съемка, выполнен сбор атмосферных осадков дождя и снега в районе 2. Братска, изучен химический состав, построена карта изменения кислотности снежного покрова в зоне влияния выбросов производства первичного алюминия и иеллюлозно-бумажного комбината. В основе применяемых гис-технологий должны находиться достоверные данные системных или иных натурных наблюдений за изменением показателей в окружающей среде в корреляиии с фактическими условиями того или иного периода (применяемое сырье, скорость ветра, количество осадков, температура воздуха).

Ключевые слова: фтор, сера, натрий, выбросы, снежный покров, атмосферные выпадения.

(C) Siberian Federal University. All rights reserved

* Corresponding author E-mail address: fduecn@bk.ru 


\section{Введение}

Байкальский регион расположен в центре Восточной Сибири на территории в основном с практически ненарушенными природными экосистемами за исключением локальных участков в районах расположения городов, лесозаготовительных, обогатительных горно-добывающих предприятий, нефтяных, газовых месторождений. Ненарушенные территории - основа устойчивого экологического равновесия как в регионе, так и в Северном полушарии в целом. В этой связи необходимо принимать меры по сокращению и предотвращению загрязнения ОС на любых стадиях хозяйственной деятельности.

Частью Байкальского региона является Иркутская область. В Иркутской области находятся два действующих (Братск, Шелехов) и строящиеся алюминиевые заводы в г. Тайшете, пос. Богучаны. Иркутская область расположена в трех природных зонах: зона тайги (подзоны северной, средней и южной) занимает основную часть территории. Зона лесостепей и горный комплекс занимают около трети территории Иркутской области. Братск - молодой город (основан в 1955 г.), крупный промышленный центр, расположен на берегу Братского водохранилища, образовавшегося в результате перекрытия р. Ангары. Повторяемость направлений ветра в районе Братска и в районе Шелехова такова, что выбросы основной промышленной площадки направлены на городские территории. Город Шелехов - промышленный и культурный центр. ИркАЗ расположен рядом с г. Шелехов и на расстоянии 45 км от Байкала.

\section{Результаты и обсуждение исследования}

В производстве алюминия расходуется значительное количество фтористых солей, в связи с чем представляет интерес определить, какое количество фтора поступило в производство на Братский и Иркутский алюминиевые заводы. На основании расходных коэффициентов сырья [1] и количества произведенного первичного алюминия, по нашим расчетам, с 1962 г. на территорию Байкальского региона с сырьем для алюминиевых заводов поступило примерно 1,25 млн т фтора, 0,14 млн т серы и около 1,25 млн т натрия (табл. 1).

Учитывая то, что фтористые соли, поступают в производство, но не содержатся в произведенной продукции алюминиевых заводов, можно предположить, что более 1 млн т находится на территории Байкальского региона в той или иной форме и может поступать в поверхностные воды. Известно, что содержание фтора в воде Байкала не превышает 0,2 мг/л [2], ПДК в питьевой воде - 0,70-1,5 мг/л [3]. Таким образом, можно отметить недостаток фтора в воде Байкала и Ангары. По данным ежегодника [4], в 2006 г. в атмосферный воздух Братска поступило 1,465 тыс. т HF и 1,859 тыс. т твердых плохо растворимых фторидов. С учетом расхода фтора

Таблица 1. Приход $\mathrm{F}, \mathrm{Na}, \mathrm{S}$ с сырьем для производства первичного алюминия в Байкальский регион. 1962-2013 гг. (примерный расчет)

\begin{tabular}{|c|c|c|c|c|}
\hline \multirow{2}{*}{ Ингредиент } & \multirow{2}{*}{$\begin{array}{c}\text { Удельный расход, } \\
\text { кг/Al }\end{array}$} & \multicolumn{2}{|c|}{ Произведено алюминия, тыс. т } & \multirow{2}{*}{$\begin{array}{c}\text { Поступило } \\
\text { в Байкальский регион }\end{array}$} \\
\hline & & С 1962 г. на ИркАЗе & С 1966 г. на БрАЗе & \\
\hline Фтор & $\approx 25[1]$ & \multirow{3}{*}{$\approx 13800$} & \multirow{3}{*}{$\approx 36000$} & 1,25 млн т \\
\hline Cepa & $\approx 2,8(0,5 \% \mathrm{~S}$ в аноде $)$ & & & 0,14 млн т \\
\hline Натрий & $\approx 25[1]$ & & & 1,25 млн т \\
\hline
\end{tabular}


25 кг/т алюминия [1] и выпуска примерно 970000 т алюминия приход фтора на завод составит 24,250 тыс. т. Таким образом, в атмосферу города поступило $\approx 13,7$ \% фтора от прихода фтора в производство.

Наряду с фтором при производстве алюминия выбрасывается значительное количество соединений серы. По данным [1], основным источником поступления серы является анодная масса, в которой содержание серы может достичь 1,3-3,5 \%. С учетом изменения сырьевой базы содержание серы в анодной массе будет увеличиваться и, возможно, что увеличатся выбросы при существующей технологии очистки. Расход анода составляет примерно 560 кг на тонну алюминия. Выбросы $\mathrm{SO}_{2}$ на БрАЗе составили 3152 т в 2009 г. или 20 \% от прихода серы в производство (1,5 \% S в анодной массе). [5]. Наряду с фтором и серой поступает в производство алюминия натрий в составе: каустической соды, глинозема (0,2 \% натрия и калия), фторида натрия, искусственного (технического), регенерационного или флотационного криолита.

В дальнейшем в технологическом цикле при производстве алюминия происходит трансформация исходного сырья и различные фтор-, серо- и натрийсодержащие соединения локализуются или рассеиваются в окружающей среде в виде твердых, жидких, газообразных отходов.

Для достижения цели управления экологической безопасностью района целесообразно рассмотреть несколько объектов исследования в их связи: технологию получения первичного алюминия, производство ферросплавов, лесопромышленное производство, автотранспорт; снежный покров, атмосферный воздух, осадки дождя и снега, аэрозоли; климатические, синоптические, метеорологические условия в районе размещения производств. В работе использовали следующие методы исследований: снегохимическая съемка [6, 7], численное моделирование, расчет материальных потоков элементов в технологии производства алюминия и объектах окружающей среды, гис-технологии. Одной из характеристик состояния окружающей среды является $\mathrm{pH}[8,9]$ (водородный показатель) и микро- и макроэлементный химический состав фильтрата снежного покрова.

В Братске в марте 2013 г. проведена снегосъемка и установлены некоторые закономерности. Так, изменение $\mathrm{pH}$ снежного покрова зависит от содержания серы, натрия (рис. 1). Известно, что рН чистых атмосферных осадков равна 5,5 - 6,5 [10], но содержание серы в снежном по-

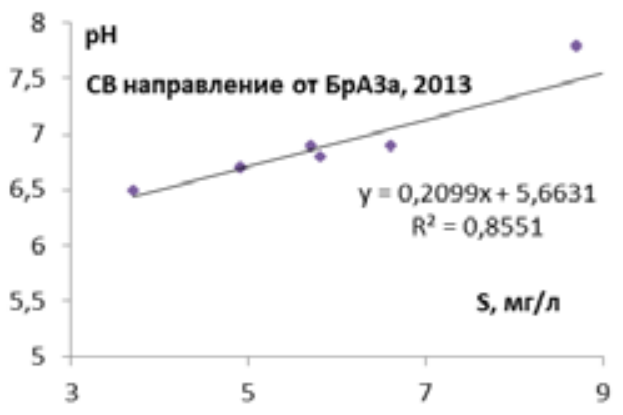

a

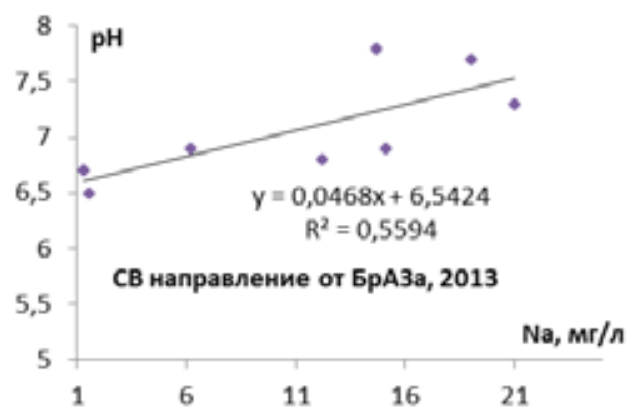

6

Рис. 1. Изменение рН о содержания S (a), $\mathrm{Na}$ (б) в фильтрате снеговой воды. Братск, март 2013 г. 


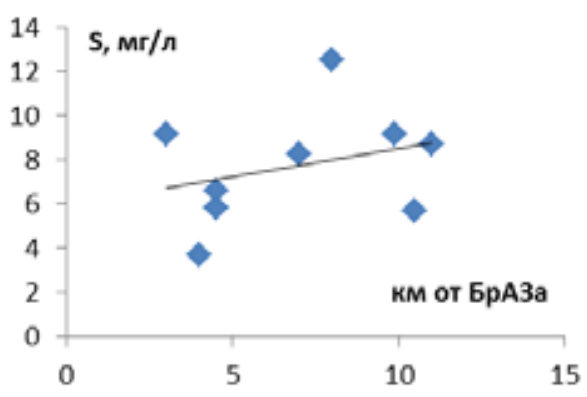

Рис. 2. Содержание серы в фильтрате снеговой воды и расстояние от БрАЗа, март 2013 г.

крове связано не только с деятельностью БрАЗа. Есть иные источники, о чем свидетельствует отсутствие корреляции между содержанием серы и расстоянием от завода в данной области исследования на расстоянии до 11 км (рис. 2).

Величина $\mathrm{pH}$ атмосферных осадков и снеговой воды обычно обусловлена в основном присутствием карбонатов, сульфат-ионов и т.д. [10]. Высокая величина рН в снежном покрове (рис. 3) района исследования в 2014 г. обусловлена применением каустической соды в технологии «мокрой» газоочистки выбросов на БрАЗе; кроме того, натрий входит в состав материалов для производства целлюлозы (БЛПК). По данным О.В. Игнатенко [11], pН талой снеговой воды из образцов, отобранных на территории Центрального округа Братска, включающего площадку БЛПК, расположенную на расстоянии 1-2 км от жилых домов, находиться в интервале от 7,8 до 7,94.

По мнению авторов [11], максимальные значения $\mathrm{pH}-7,65$ и 7,94 - наблюдаются в зоне воздействия выбросов предприятий ОАО «Группа «Илим». Таким образом, наличие натрийсодержащих примесей в атмосфере пока предотвращает опасное закисление атмосферных осадков и снежного покрова.

На основании экспериментальных данных по интенсивности нагрузки ионов фтора на снежный покров в районе влияния выбросов ИркАЗа и модели осаждения атмосферных аэрозолей также выполнен прогноз скорости коррозии Ст. 3 в районе выбросов [12].

Одним из методов геоэкологии является построение карт распределения загрязняющих веществ.

Построение карт изолиний позволяют выявить основные источники выбросов и т.д. (рис. 3). На картосхеме отображены изолинии и локальные максимумы $\mathrm{pH}$, соответствующие точкам отбора проб с максимальными значениями и приуроченные к промышленным объектам. На современном уровне развития информационных технологий оптимальным выбором для информирования заинтересованных специалистов являются веб-средства представления результатов наблюдения. Известно, что на основе интернет-ресурса или авторской программы можно создать новую технологию представления результатов. Желательно применять технологии, которые предполагают наличие динамического визуального интерфейса, позволяющие масштабировать изображение, менять растровые подложки, сопоставлять в рамках одной карты результаты исследований разных процессов и явлений. Такой подход создает качественно новый уровень обработки результатов наблюдений и выступает важным инструментом систе- 


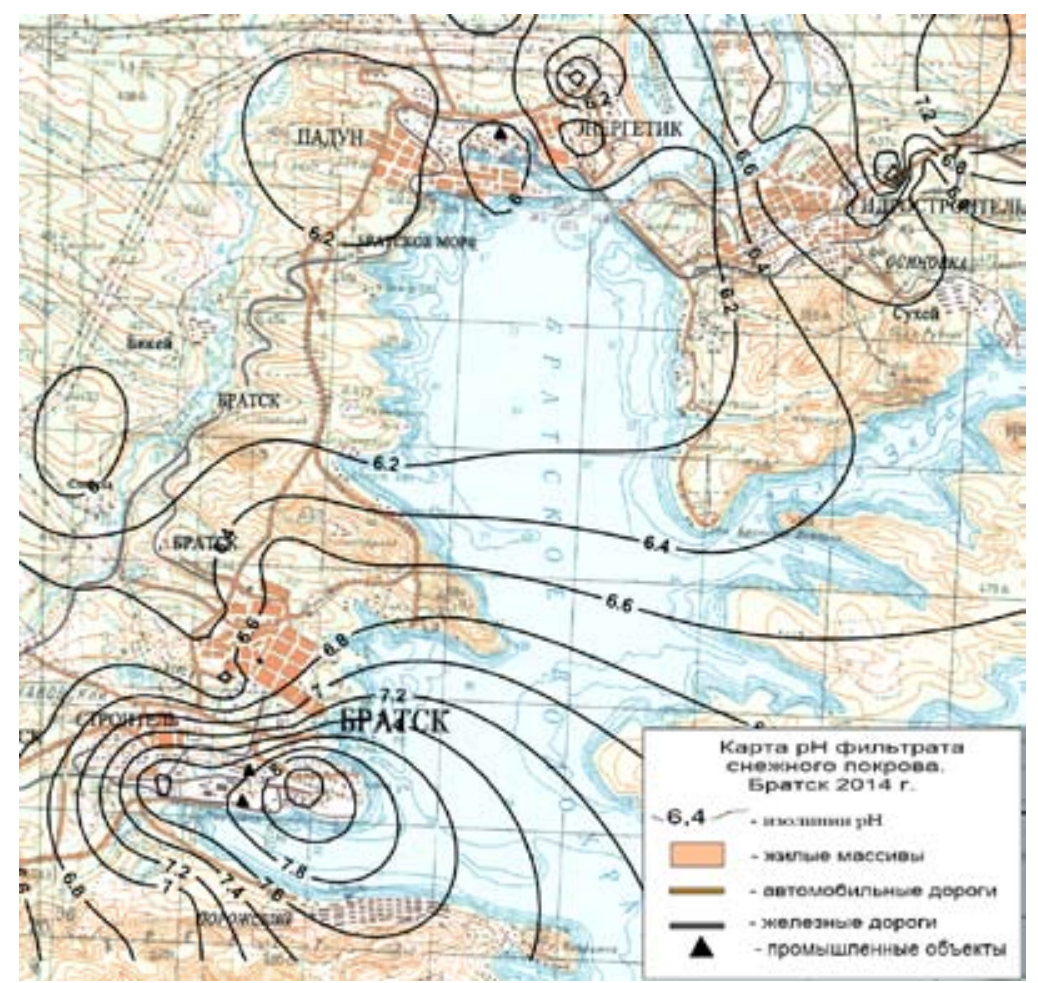

Рис. 3. Распределение рН в снежном покрове г. Братска, март 2014 г.

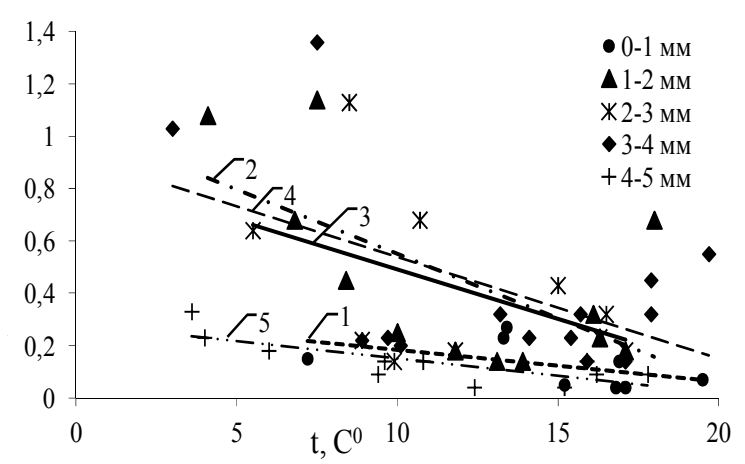

Рис. 4. Зависимость содержания ионов фтора в атмосферных осадках дождя от температуры приземного слоя воздуха для различных интервалов количества осадков в день. Цифрами обозначены линии регрессии для соответствующих интервалов (1 - 0-1,0 мм/день; 2 - 1,0 -2,0 мм/день; 3 - 2,0-3,0 мм/день; 4- 3,0-4,0 мм/день; 4- 4,0-5,0 мм/день)

мы технолого-экологического мониторинга. В основе применяемых технологий должны находиться достоверные данные системных натурных наблюдений за изменением показателей в окружающей среде в корреляции с фактическими условиями того или иного периода (применяемое сырье, скорость ветра, количество осадков, температура воздуха [12] и т.д.). Так, содержание фтора в осадках дождя зависит от температуры атмосферного воздуха, эта корреляция проявляется, если учесть количество осадков (рис. 4). Чем ниже температура атмосферного 
воздуха, тем выше концентрация. Можно сделать вывод, что фториды в атмосфере находятся преимущественно в форме газообразных соединений в данной точке измерений, т.к. известно, что при понижении температуры растворимость газов увеличивается. Не учитывая эти и другие метеорологические факторы, можно сделать некорректный вывод, например, о динамике содержания фтора в осадках дождя, снега или снежном покрове.

\section{Выводы}

В г. Братске в марте 2013 г. проведена снегохимическая съемка, исследован химический состав, построена карта изменения $\mathrm{pH}$ в снежном покрове, показано влияние температуры на содержание фтора в осадках дождя. Таким образом, применение в качестве объекта исследования снежного покрова и атмосферных выпадений позволит совершенствовать промышленный мониторинг и скорректировать принятие технологических решений для минимизации негативного воздействия технологий, т.е. улучшить управление экологической безопасностью производств, что позволит повысить эффективность производства и улучшить качество жизни населения.

Исследование выполнено при частичной финансовой поддержке, ФЦП № 847 от 21.08.2012 2., государственного задания 127/2014 Министерства образования и науки.

\section{Список литературы}

[1] Терентьев, В.Г. Сысоев А.В., Гринберг И.С.и др. Производство алюминия. М.: Металлургия, 1997. $150 \mathrm{c}$.

[2] Гребенщикова В.И. и др. Геохимия окружающей среды Прибайкалья (Байкальский геоэкологический регион). Новосибирск: Гео, 2008. 234 с.

[3] ГН 2.1.5.1315-03 Предельно допустимые концентрации химических веществ в воде водных объектов хозяйственно-питьевого и культурно-бытового водопользования [Электронный pecypc]: утв. гл. сан.вр. РФ 27.04.03. Введ. 15. 06. 03 г. Режим доступа: http://portal-ot -saratov. $\mathrm{ru} / \mathrm{page}$.

[4] Ежегодник 2007 года // Федеральная служба России по гидрометеорологии и мониторингу окружающей среды. Иркутское управление по гидрометеорологии и мониторингу окружающей среды. Иркутский территориальный центр гидрометеорологии и мониторингу окружающей среды. Иркутск, 2008.

[5] Государственный доклад о состоянии и об охране окружающей среды Иркутской области в 2009 году. Иркутск: Министерство природных ресурсов и экологии, 2009. $585 \mathrm{c}$.

[6] Василенко В.Н., Назаров И.М., Фридман Ш.Д. Мониторинг загрязнения снежного покрова. Л.: Гидрометеоиздат, 1985. 183 с.

[7] РД 52.04.186-89 «Руководство по контролю загрязнения атмосферы» Госкомитет СССР по гидрометеорологии и Министерство здравоохранения СССР. М., 1991. $683 \mathrm{c}$.

[8] Zhiwen Dong, Mingjun Zhang, Zhongqin Li et. al. // Journal of Geographical Sciences. August 2009. Vol. 19. Issue 4. P. 416-426. 
[9] Zongxing Li, Yuanqing He, Wilfred H. Theakstone, et. al. // Journal of Sciences. April 2010. Vol. 21. Issue 2. P. 157-165.

[10] Свистов П.Ф., Периина Н.А., Полищук А.И. // Федеральная служба по гидрометеорологии и мониторингу окружающей среды РОСГИДРОМЕТ. Государственное учреждение «Главная геофизическая обсерватория им. А.И. Воейкова». М.: Метеоагентство Госгидромета, 2006. $227 \mathrm{c}$.

[11] Игнатенко О.В., Мещерова Н.А. // Эколого-биологические проблемы Сибири и сопредельных территорий: материалы 2-й НПК с междунар. участием. Нижневартовск: Нижневарт. гум. ун-т, 2011. С. 236-239.

[12] Янченко Н.И., Яскина О.Л. // Оптика атмосферы и океана. 2014. 27. № 3. С. 247-249. 